Research Article

\title{
An Experimental Study on Wetting of Coal Dust by Surfactant Solution
}

\author{
Yidan Jiang, ${ }^{1}$ Pengfei Wang $\mathbb{D}^{1,2}$ Ronghua Liu, ${ }^{1,3}$ Ye Pei, ${ }^{1,3}$ and Gaogao $W u^{1}$ \\ ${ }^{1}$ School of Resource, Environment \& Safety Engineering, Hunan University of Science \& Technology, Xiangtan 411201, China \\ ${ }^{2}$ Department of Civil and Architectural Engineering and Mechanic, University of Arizona, Tucson, AZ 85721, USA \\ ${ }^{3}$ Work Safety Key Lab on Prevention and Control of Gas and Roof Disasters for Southern Coal Mines, \\ Hunan University of Science \& Technology, Xiangtan 411201, China \\ Correspondence should be addressed to Pengfei Wang; pfwang@sina.cn
}

Received 10 October 2019; Accepted 14 December 2019; Published 31 March 2020

Academic Editor: Michael Aizenshtein

Copyright (C) 2020 Yidan Jiang et al. This is an open access article distributed under the Creative Commons Attribution License, which permits unrestricted use, distribution, and reproduction in any medium, provided the original work is properly cited.

\begin{abstract}
Surfactants can improve the wetting performance of the dust-reduction spraying water, thus improving the dust-reduction effect by spray. In this study, the performance of surfactant solution in wetting coal dust was investigated through experiments. In addition, the effects of surfactant type, mass fraction, metamorphic degree of coal, particle size, and additives were investigated. According to the results of surface tension experiments, the surface tension of the solution decreased with the increase of the concentration of surfactant. However, after reaching CMC, the surface tension did not have significantly decrease. SDBS and OP10 had higher efficiency in decreasing the surface tension than the other two types of surfactants. The addition of sodium sulfate additives can further reduce the surface tension of the surfactant solution by a limited range. The coal dust wetting experiment showed that with the increase in the concentration of the surfactant, the contact angle of the droplets on the coal dust tablet was continuously reduced, and the wettability of the solution was continuously improved. The wettability of the OP-10 solution was optimal. At the same concentration, the minimum contact angle can be obtained in the OP-10 solution. As the contact angle of the coal dust increased, the growth rate in the coal dust reverse osmosis moisture absorption of the surfactant solution relative to the pure water increased. After the addition of sodium sulfate, the reverse osmosis moisture absorption of coal dust increased to varying degrees. In addition, as the concentration of additives increased, the moisture absorption of coal dust increased.
\end{abstract}

\section{Introduction}

Coal is the main energy source in China, accounting for about two-thirds of total primary energy consumption [1-5]. Plenty of environmental problems and natural disasters may occur during mining, i.e., roof fall, gas, fire, and dust pollution [6-9]. A large amount of dust is generated during the coal mining process, causing the high-concentration dust environments for the workers, which poses a serious threat to their health and safety [10-15]. At present, the underground coal mining operations mainly use the dust-prevention measures including prefilling coal with water, dust control by ventilation, dust purification by dust collector, dust reduction via spraying, and dust blocking in an enclosed area [16-20]. Dust reduction via spraying is cost economic, simple, and practical and thus has become the main dust-prevention technology for coal mines [21-27]. The surface of coal dust usually contains a large amount of hydrophobic nonpolar groups. As a result, the coal dust has a certain degree of hydrophobicity. At the same time, due to the large surface tension of spraying water in the conventional dust reduction, the coal dust in the air, especially the respiratory dust, is not easily wetted and captured by the droplets. As a result, the dustreduction efficiency via spraying is generally low [28-31]. The surfactant can adsorb to the solid-liquid and gas-liquid interface, reduce the interfacial tension, improve the wettability of the spraying water, and improve the dust-reduction efficiency via spraying [32-36].

At present, the researchers in China and other countries have performed extensive studies on the physical properties 
of surfactant solutions. Surface tension is an important physical parameter for liquids. For a long time, the surface tension of surfactant solutions has been investigated with details, including the effects of surfactant types and mass concentrations, as well as the corresponding critical micelle concentrations (CMC) [37-41]. Some researchers also studied the surface tension of surfactant complex solution. The surface tension of the surfactant complex solution of different types and proportions was investigated [42-44]. He et al. studied the effects of inorganic salts such as $\mathrm{NaCl}$, $\mathrm{CuCl}_{2}$, and $\mathrm{ZnSO}_{4}$ on the surface tension of sodium dodecyl sulfate (SDS) solution. The results showed that the surface tension of SDS solution decreased with the increase of inorganic salt concentration within a certain range [45]. Du and Zeng investigated the change of CMC of surfactant under the action of metal salt. The results showed that the CMC of SDS and CTAB decreased with the increase of metal ion concentration. In addition, this conclusion was explained by the counter-ion effect and the entropy determination effect [46].

Through the contact angle and reverse osmosis experiments, the researchers investigated the wetting performance of the surfactant solution for the coal dust. The results showed that adding surfactant in pure water can effectively improve the wetting ability for coal dust. The degree of the improvement depended on the type of surfactant and the mass concentration [47-49]. Yang et al. found that the ions ionized from anionic surfactants were usually negatively charged and repelled the coal dust with negative charges on the surface. The repelling force was not conducive to the adsorption of surfactants on the surface of coal dust. As a result, the anionic surfactants had lower wettability than the nonionic surfactants [50]. $\mathrm{Wu}$ and $\mathrm{Gu}$ performed experimental and theoretical analysis to study the effect of additives on the wetting ability of anionic surfactant solutions. The results showed that the addition of $\mathrm{Na}_{2} \mathrm{SO}_{4}$ to the anionic surfactant solution can greatly improve the wetting ability of the solution [51]. Tessum investigated the capture efficiency of charged dust particles by the droplets of different surfactant solutions. The experimental results showed that the types of surfactants can affect the collection efficiency of the charged dust particles. In addition, the nonionic surfactant had better dust-collection performance [52]. Jiang et al. performed an experiment on the surfactant complex. The experimental results showed that the wetting performance of the solution on coal dust can be optimized by compounding [53]. Liu et al. applied the surfactants to the site of the 1305 fully mechanized excavation face of Dongtan Coal Mine in China. The field test results showed that the dust-reduction efficiency via spraying in the fully mechanized excavation face was greatly improved by the addition of surfactants. Especially, the improvement in the dust-reduction efficiency was more significant for the respirable dust [54].

Currently, researchers from various countries have made great progress in the studies on the surface tension of surfactant solution and the wetting performance for coal dust. Especially, the influence of type and mass concentration of surfactants were intensively investigated. However, in the previous studies, a single type of coal dust was used in most tests, the particle size range of coal dust was relatively wide, and the degrees of metamorphism and the particle size of coal dust were rarely considered. The surfactant solutions with different degrees of metamorphism and different particle sizes have different wettability of coal dust and exhibit different degrees of improvement compared to pure water. However, the influences of these two factors were rarely studied in previous reports. Thus, at the application site of coal mine engineering, there was a lack of theoretical guidance for the design of dust-reduction system via spraying and the selection of surfactants for different types of coal dust. Therefore, in this study, the wettability of coal dust by surfactant solutions was investigated. In addition, the influences of the surfactant type, mass concentration, metamorphism degree of coal, particle size of coal dust, and additives on the wetting ability were analyzed. The results of this study can provide theoretical guidance for the application of surfactants in dust reduction via spraying in the field of coal mine.

\section{Materials and Methods}

2.1. Materials. Based on the surfactant formulations, patents, and related academic papers on dust reduction via spraying in coal mine in various countries, two types of surfactants, i.e., anionic and nonionic, were selected from various surfactants in this study [55-59]. A total of four reagents were used for experiments. The surfactants used in the experiments are shown in Table 1. According to the previous studies, inorganic salt additives can effectively improve the wetting ability of surfactants. In order to investigate the effect of additives on the physical properties of surfactant solutions, sodium sulfate was chosen as an additive.

In the experiments on the wetting ability, six different grades of coal dust from China's major coal production bases were used. According to the degree of metamorphism, the coal samples in the experiment were in the following order: lignite in Guangxi Donghuai Coal Mine, gas coal in Shandong Baodian Coal Mine, fat coal in Hebei Qianjiaying Coal Mine, coking coal in Shanxi Wanfeng Coal Mine, lean coal in Guizhou Fa'er Coal Mine, and anthracite in Hunan Motian Mine. The six coal samples were crushed by a pulverizer for $1 \mathrm{~min}$ and sieved by a 100-mesh standard industrial sieve. Then, the coal dust sample was dried in a vacuum drying oven for 480 minutes at the temperature of $80^{\circ} \mathrm{C}$ and placed in a sealed bag for late use. The industrial indicators and characteristic particle sizes of the six coal samples are shown in Table 2.

In order to investigate the improvement effect of surfactant solution on the wetting performance of the dust with different particle sizes, coking coal with poor wetting performance was selected. Six types of coal dust samples with different particle size grades were prepared by industrial sieves with different specifications. The coal dust particle size grades were numbered sequentially in the order of large to small. The analysis on the particle size of coal dust samples was performed using an LS13320 laser particle size analyzer. The distribution of the particle size of the coal dust sample is shown in Figure 1. 
TABLE 1: Four selected surfactants for the experiment.

\begin{tabular}{lcccc}
\hline Chemical name of surfactants & Abbreviation & Species & Purity & Chemical formula \\
\hline Sodium dodecyl sulfate & SDS & Anion & Analytical purity & $\mathrm{CH}_{3}\left(\mathrm{CH}_{2}\right)_{11} \mathrm{OSO} \mathrm{OSa}_{3}$ \\
Sodium dodecyl benzene sulfonate & SDBS & Anion & Analytical purity & $\mathrm{CH}_{3}\left(\mathrm{CH}_{2}\right)_{11}-\mathrm{Ph}_{-} \mathrm{SO}_{3} \mathrm{H}$ \\
Sorbitan monooleate polyoxyethylene ether & Tween-80 & Nonionic & Analytical purity & $\mathrm{C}_{6} \mathrm{H}_{8} \mathrm{O}\left[\mathrm{O}_{(\mathrm{CH}}\left(\mathrm{CH}_{2} \mathrm{O}\right)_{20} \mathrm{OH}\right] \mathrm{OOCR}$ \\
Alkylphenol ethoxylate & OP-10 & Nonionic & Analytical purity & $\mathrm{C}_{8} \mathrm{H}_{17} \mathrm{C}_{6} \mathrm{H}_{4} \mathrm{O}\left(\mathrm{CH}_{2} \mathrm{CH}_{2} \mathrm{O}\right)_{10} \mathrm{H}$ \\
\hline
\end{tabular}

TABLE 2: Industrial analysis indexes and characteristic particle sizes of experimental coal samples.

\begin{tabular}{lcccccccc}
\hline No. & Coal property & Mad (\%) & Aad $(\%)$ & Vad $(\%)$ & FCad $(\%)$ & $D_{10}(\mu \mathrm{m})$ & $D_{50}(\mu \mathrm{m})$ & $D_{90}(\mu \mathrm{m})$ \\
\hline 1 & Lignite (LC) & 1.59 & 10.75 & 39.87 & 49.79 & 21.43 & 109.53 \\
2 & Gas coal (GC) & 2.02 & 10.27 & 34.02 & 53.69 & 32.01 & 123.98 \\
3 & Fat coal (FC) & 2.36 & 10.87 & 34.42 & 56.71 & 11.86 & 100.89 \\
4 & Coking coal (CC) & 2.56 & 12.72 & 14.94 & 69.78 & 6.52 & 76.19 & 195.30 \\
5 & Meager-lean (MLC) & 3.56 & 13.18 & 15.39 & 67.87 & 20.79 & 111.91 & 231.72 \\
6 & Anthracite (AC) & 3.25 & 23.50 & 5.10 & 68.15 & 7.98 & 81.86 \\
\hline
\end{tabular}

"Mad" denotes air-dried moisture content in the air, "Aad" denotes air-dried ash content in the air, "Vad" denotes air-dried volatile content in the air and "FCad" denotes the content of fix carbon. $D_{10}, D_{50}$, and $D_{90}$ are characteristic particle diameters, i.e., the volume of the particles with the diameters below $D_{10}$, $D_{50}$, and $D_{90}$ occupy $10 \%, 50 \%$, and $90 \%$ of total particle volume, respectively.

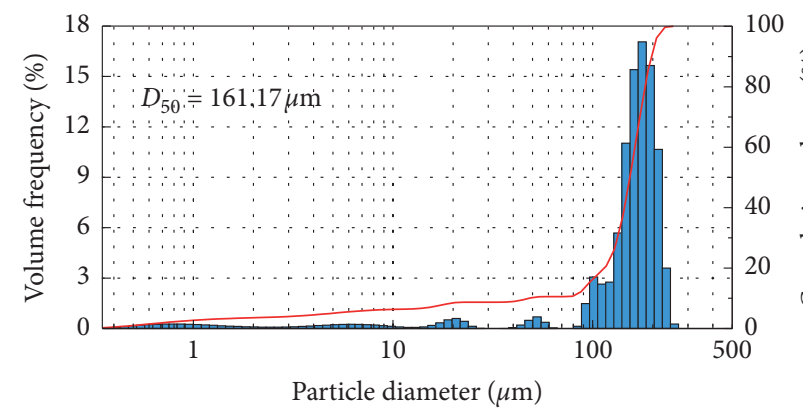

Volume frequency

Cumulative volume

(a)

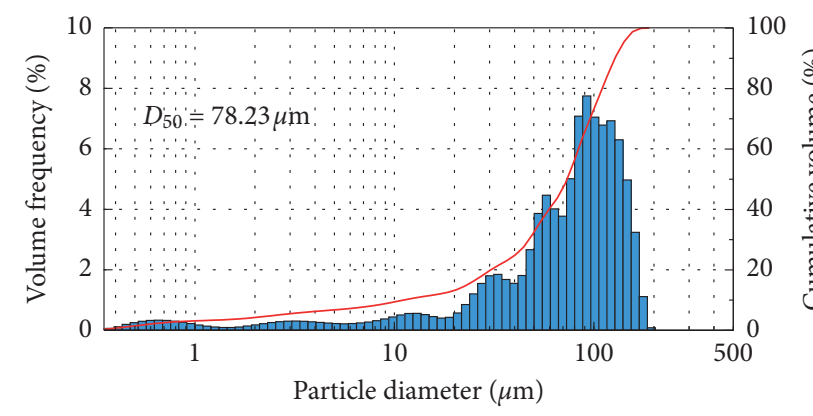

Volume frequency __ Cumulative volume

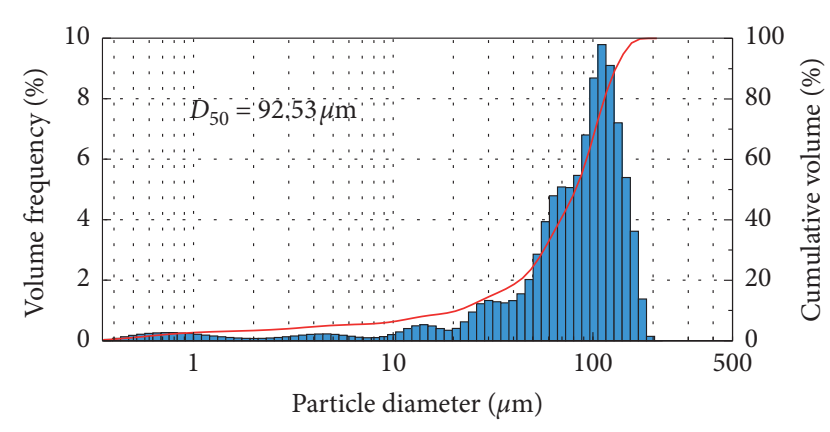

Volume frequency

Cumulative volume

(b)

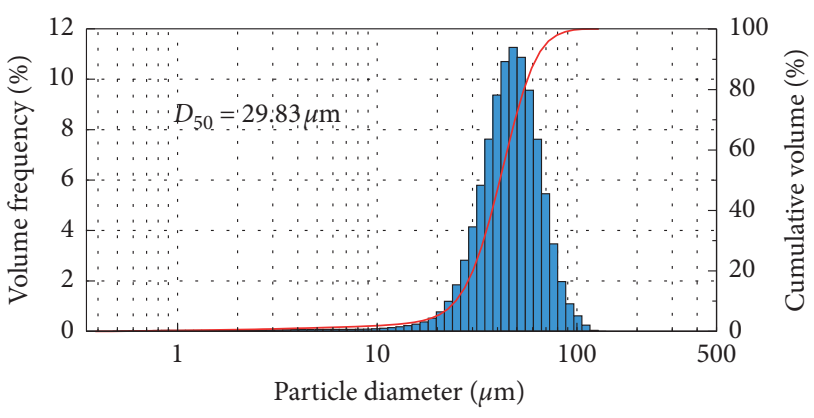

Volume frequency

Cumulative volume

Figure 1: Continued. 


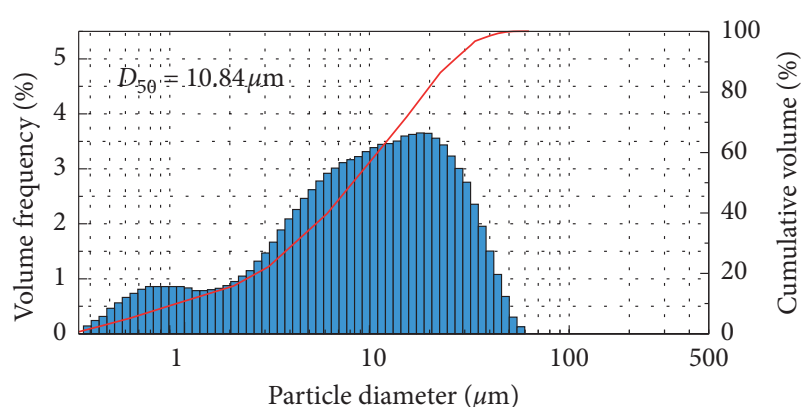

Volume frequency - Cumulative volume

(e)

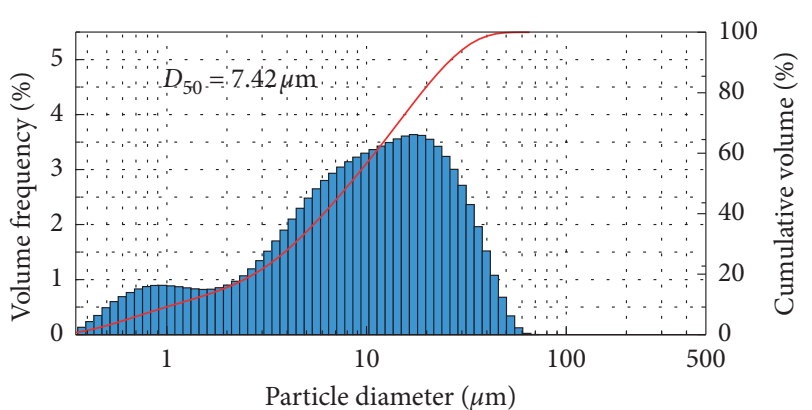

Volume frequency

Cumulative volume

(f)

Figure 1: Coal dust particle size distribution of coking coal sample: (a) No. 4-1, (b) No. 4-2; (c) No. 4-3; (d) No. 4-4; (e) No. 4-5; (f) No. $4-6$.

\subsection{Experimental Scheme}

2.2.1. Surface Tension. Surface tension is an important parameter affecting the wetting ability of surfactant solutions. The surface tension of the four surfactant solutions at different mass concentrations was measured using a German Kruss K20 surface tension meter. In the experiment, a total of six mass concentrations of the surfactants were set, i.e., $0 \%, 0.00005 \%, 0.0005 \%, 0.005 \%, 0.05 \%$, and $0.5 \%$. Then, according to the efficiency and performance of surface tension reduction, an anionic surfactant and a nonionic surfactant were selected from the four surfactants and used in the additive effect test. The $\mathrm{Na}_{2} \mathrm{SO}_{4}$ was added to the surfactant solutions with the mass concentrations of $0.00005 \%, 0.0005 \%$, and $0.005 \%$. Then, the surface tension was measured to investigate the effect of the additives on the surface tension of the surfactant solution. At the same time, the effect of the mass concentration of the additives was also investigated. Six mass concentrations were set, which were $0.1 \%, 0.2 \%, 0.3 \%, 0.4 \%, 0.5 \%$, and $0.6 \%$, respectively. In the surface tension test, the temperature of all the solutions was $25^{\circ} \mathrm{C}$.

2.2.2. Wetting Ability. There were a total of 4 test groups in the experiment on the wetting ability of the surfactant solution. In the first group, the effects of surfactant type and mass concentration were tested, and the coal dust of coking coal was selected. The above four types of surfactant solutions and six mass concentrations were combined to obtain 24 types of solution samples. The wetting ability of the solution samples was tested. In the first set of experiments, the contact angle was used to evaluate the wetting ability of the surfactant solution. First, $400 \mathrm{mg}$ of pulverized coal was added to the mold, and the mold was placed in a bench-top powder tableting machine. A molding pressure of $50 \mathrm{MPa}$ was applied for 1 minute to prepare a cylindrical test piece with smooth surface and a thickness of about $2 \mathrm{~mm}$. The contact angle was measured using a CA100B contact angle measurement instrument. For each coal dust sample, three test pieces were measured and the average value of the test results was obtained [60].

In groups 2 and 3 , the influences of the degree of metamorphism and the particle size of the coal dust were tested, respectively. In order to investigate the wettability of the coal dusts with different degrees of metamorphism by surfactants, the six coal samples in Table 2 were selected. At the same time, the OP-10 surfactant with strong wetting ability in the first group of experiments was selected. The mass concentration was fixed at $0.05 \%$, and the wettability of various coal dusts by the surfactant solution was analyzed. At the same time, the wetting ability of pure water for various coal dusts was also measured and compared with the surfactant solution. The improvement of the wettability of various coal dusts by surfactant solution relative to pure water was investigated. The surfactant type and mass concentration were kept unchanged, and the six types of coal dust in Figure 1 were selected to investigate the improvement of the wettability of coal dust with different particle size by surfactant solution. In group 4 of the experiment, the influence of the additives was investigated. The surfactant of OP-10 was selected in this group. The type and the concentration of the additive were the same as that in the surface tension test. The selected coal dust was the medium coke coal with the label of 4 in Table 1 . According to the results in the experiments in groups 2-4, the surfactant solution and additives only had little effect on the wettability under certain working conditions, while the test with contact angle might have a large error. In the above three groups of experiments, the reverse osmosis moisture was used to evaluate the wetting ability of the solution. The moisture absorbing performance of the coal dust sample was measured using a custom-designed reverse osmosis device. First, $3000 \mathrm{mg}$ of coal sample was placed into a glass test tube with a diameter of $10 \mathrm{~mm}$. The glass test tube was sealed with filter paper and weighed. Then, the glass test tube was into the sink upside down, and water was added to the sink to drown the glass tube. After 4 hours, the glass test tube was taken out and reweighed, and the amount of absorbed water by coal dust was calculated $[61,62]$. The measurement devices for the wettability of coal dust are shown in Figure 2. 


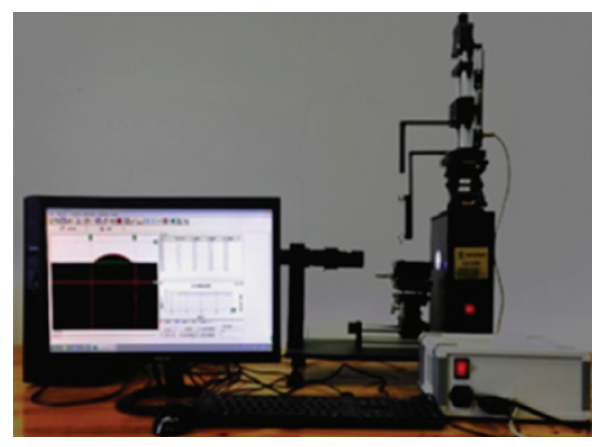

(a)

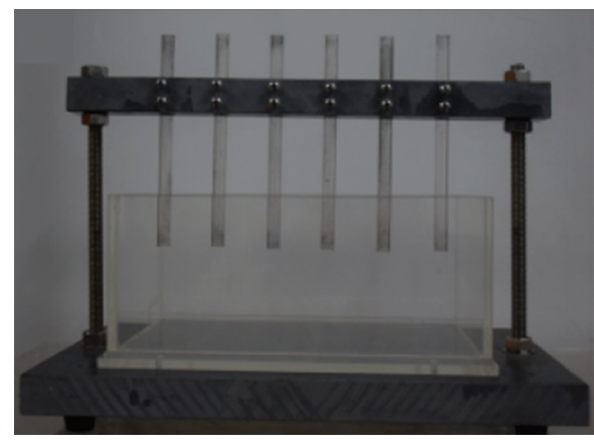

(c)

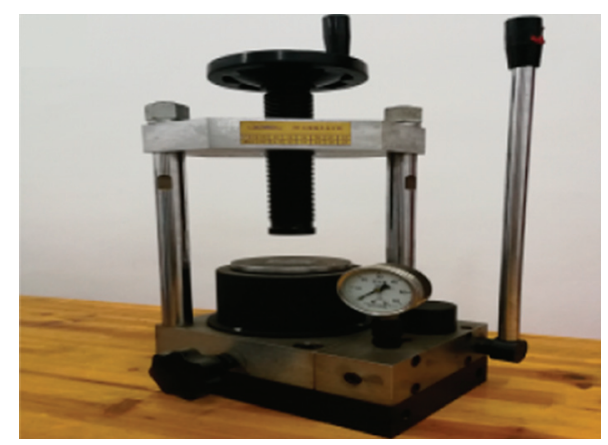

(b)

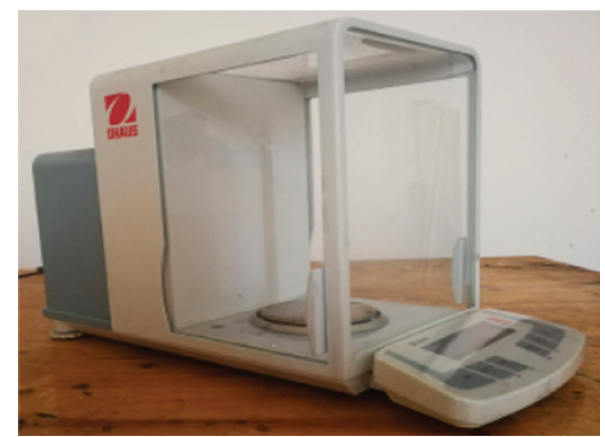

(d)

Figure 2: Measurement device of coal dust wettability: (a) CA100B contact angle measuring device; (b) powder compressing machine; (c) reverse osmosis device; $(\mathrm{d})$ electronic analysis balance.

\section{Results and Analysis}

\subsection{Surface Tension Test}

3.1.1. Effect of Surfactant. Table 3 shows the surface tension of the four surfactant solutions at different mass concentrations.

From Table 3, the surface tension of the four surfactant solutions gradually decreased with the increase of concentration, indicating that the four surfactants had similar characteristics and similar ability to change the surface tension of pure water. From the surface tension data in Table 3, it was also found that when the concentration of the surfactant solution was low and the surface tension drastically decreased with the increase of the concentration. When the mass concentration reached a certain value, the surface tension approached a constant value. Due to the amphiphilic structure, the surfactant molecules had positive adsorption on the surface of the aqueous solution, resulting in a significant decrease in the surface tension of the solution. When the concentration of amphiphilic molecules in the aqueous solution reached a certain value, the adsorption at the interface were saturated, and the amphiphilic molecules form colloidal aggregated in the aqueous solution. The colloidal aggregates were in a thermodynamically stable state, thus the surface tension of the solution did not drop significantly with the increase of the concentration. In this condition, the concentration was called the CMC.

In order to quantitatively characterize the ability of surfactants to reduce the surface tension of a solution, Rosen et al. proposed a negative logarithm, $\mathrm{p} c_{20}$, of the required concentration of surfactant to reduce the surface tension of
TABle 3: Surface tension of four surfactant solutions at different mass concentrations.

\begin{tabular}{lccccc}
\hline \multirow{2}{*}{ No. } & \multirow{2}{*}{$c_{\mathrm{m} 1}(\%)$} & \multicolumn{4}{c}{ Surface tension $(\mathrm{mN} / \mathrm{m})$} \\
& & SDS & SDBS & Tween-80 & OP-10 \\
\hline 1 & 0 & 73.0 & 71.3 & 73.0 & 72.0 \\
2 & 0.00005 & 59.5 & 58.0 & 62.6 & 54.8 \\
3 & 0.0005 & 51.5 & 42.8 & 47.4 & 43.8 \\
4 & 0.005 & 35.9 & 28.8 & 43.5 & 32.6 \\
5 & 0.05 & 31.3 & 28.4 & 40.8 & 31.9 \\
6 & 0.5 & 30.4 & 28.0 & 39.7 & 32.5 \\
\hline
\end{tabular}

water by $20 \mathrm{mN} \cdot \mathrm{m}^{-1}$. The negative logarithm of the concentration was defined as the surface tension reduction efficiency of the surfactant:

$$
\mathrm{p} c_{20}=-\lg c_{\pi=20}
$$

where $c_{\pi=20}$ is the surfactant concentration corresponding to the surface tension reduction of water by $20 \mathrm{mN} \cdot \mathrm{m}^{-1}$. When the value of $\mathrm{p} c_{20}$ is higher, the surface surfactant can effectively reduce the surface tension of water at a lower concentration, thus the adsorption efficiency of the solution surface is higher. From the data in the table, SDBS and 0P-10 had higher efficiency in reducing the surface tension than the other two surfactants. The surface tension of both SDBS and 0P-10 solutions dropped below $45 \mathrm{mN} / \mathrm{m}$ at a mass concentration of $0.0005 \%$. In order to obtain the CMC of each surfactant, the reduction rates of surface tension by the four surfactants were determined in different concentration intervals, as shown in Figure 3. 


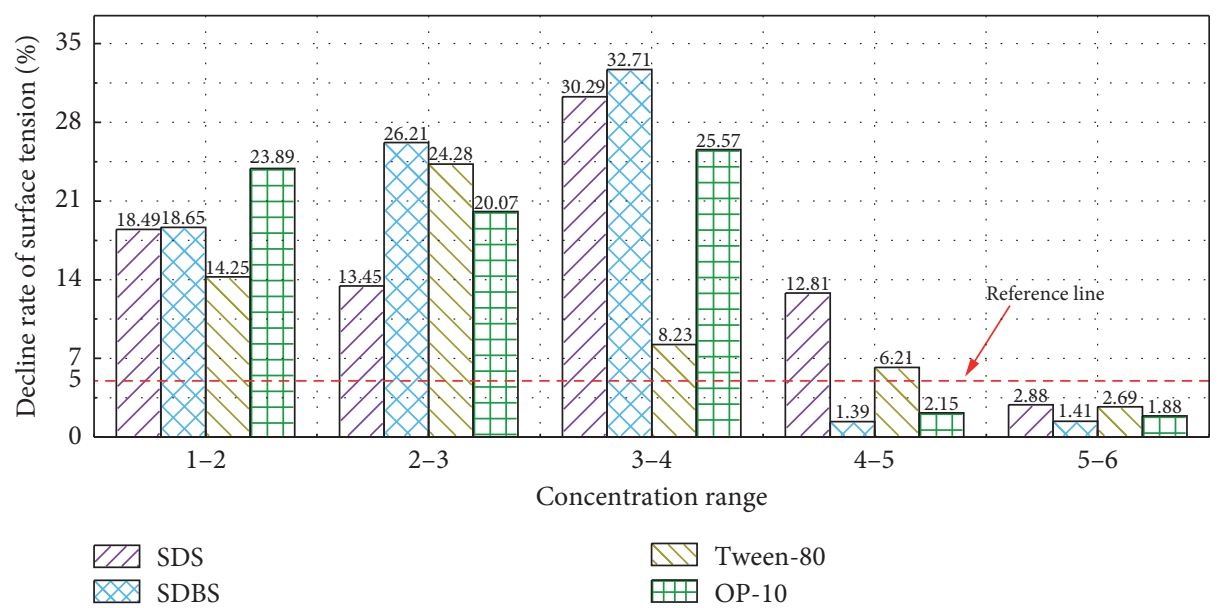

FIGURE 3: The reduction rate of the surface tension of the four surfactants was obtained in different mass concentration intervals.

From Figure 3, in the last concentration interval, i.e., within the concentration range of $0.05 \%$ to $0.5 \%$, the reduction rates of surface tension for the four surfactant solutions were all less than 3\%. For the surfactants of SDBS and OP-10, the surface tension decreased to less than $3 \%$ in the concentration range of $0.005 \%$ to $0.05 \%$. The above data prove that the CMC value was about $0.005 \%$ for SDBS and OP-10 and about $0.05 \%$ for the other two surfactants. Therefore, SDBS and OP-10 were superior to the other two surfactants in reducing the surface tension. Among the four surfactants, SDBS can obtain the minimum surface tension at the same mass concentration, whose surface tension value corresponding to CMC was $28.8 \mathrm{mN} / \mathrm{m}$.

3.1.2. Effect of Additives. Table 4 shows the surface tension of the surfactant solution when different concentrations of sodium sulfate additives were added. From Table 4, it is seen that the addition of an inorganic salt additive can cause the decrease in the surface tension for the two surfactants. When the concentration of the surfactant solution was lower than $\mathrm{CMC}$, the addition of the additives can appropriately reduce the surface tension of the solution. As the concentration of the auxiliary agent increased, the surface tension continuously decreased and finally stabilized. However, in general, the decrease in the surface tension of the solution by the additives was not significant, especially when the surfactant solution approached or reached the CMC.

When an inorganic salt was present in the surfactant solution, the counter-ion in the salt neutralized the hydrophilic group charge of the surfactant, lowered the phase potential, and further reduced the surface tension of the solution. Comparing the change of the surface tension of the two surfactant solutions in Table 4, it can be seen that the reduction of the surface tension of the ionic surfactant by the inorganic salt was more significant than that of the nonionic surfactant. For example, when the surfactant concentration was $0.00005 \%$, with the addition of $0.6 \%$ additives, the surface tension of the ionic surfactant solution was decreased by $7.41 \%$, while the surface tension of the nonionic surfactant solution was decreased by only $4.56 \%$. This is mainly due to the electrostatic interaction between the inorganic salt and the ionic surfactant solution, which compressed the thickness of the double-ion layer and reduced the repulsion between them [45]. As a result, the surfactant was easier to be absorbed on the surface of the solution and form micelles.

\subsection{Wetting Performance Test}

3.2.1. Effect of Surfactant Type and Mass Concentration. The wetting ability of surfactant solutions were closely related to their type and mass concentration. Figure 4 shows the contact angles of four surfactant solutions at different mass concentrations.

As shown in Figure 4, in general, as the concentration of the solution increased, the contact angle of the droplets on the coal dust compact was continuously reduced. According to the Young equation, the contact angle of the liquid on the solid surface has the following relationship with the interfacial tension:

$$
\cos \theta=\frac{\gamma_{\mathrm{sg}}-\gamma_{\mathrm{sl}}}{\gamma_{\mathrm{lg}}},
$$

where $\theta$ is the contact angle in the unit of ${ }^{\circ}, \gamma_{\mathrm{sl}}$ and $\gamma_{\mathrm{sl}}$ are the solid/gas interfacial tension and solid/liquid interfacial tension, respectively, which are in the unit of $\mathrm{mN} \cdot \mathrm{m}^{-1}$; $\gamma_{\lg }$ is the gas/liquid interfacial tension, i.e., the surface tension of the solution in the unit of $\mathrm{mN} \cdot \mathrm{m}^{-1}$. When a surfactant was present in the solution, its adsorption at the solid/liquid and gas/liquid interfaces enhanced the hydrophilicity of the coal dust surface, which was originally hydrophobic, causing significant decrease of $\gamma_{\mathrm{sl}}$ and $\gamma_{\mathrm{lg}}$. As a result, the contact angle became small. When the surfactant concentration was continuously increased, the adsorption amounts of the surfactant at the solid/liquid and gas/liquid interfaces were continuously increased, thus $\gamma_{\mathrm{sl}}$ and $\gamma_{\mathrm{lg}}$ were continuously decreased and the contact angle was continuously decreased. This phenomenon can also be observed from the projection of the contact angle in Figure 5(a). Comparing the wetting abilities of the four surfactants at the same mass 
TABLE 4: The effect of sodium sulfate additive on the surface tension of surfactant solution.

\begin{tabular}{|c|c|c|c|c|c|c|}
\hline \multirow[b]{2}{*}{$c_{\mathrm{m} 2}(\%)$} & \multirow{2}{*}{$\begin{array}{c}\text { OP-10 } \\
0.00005 \%\end{array}$} & \multicolumn{5}{|c|}{ SDBS } \\
\hline & & $0.0005 \%$ & $0.005 \%$ & $0.00005 \%$ & $0.0005 \%$ & $0.005 \%$ \\
\hline 0 & 54.8 & 43.8 & 32.6 & 58.0 & 42.8 & 28.8 \\
\hline 0.1 & 54.5 & 43.1 & 32.6 & 57.1 & 42.4 & 29.7 \\
\hline 0.2 & 54.3 & 42.7 & 32.4 & 56.6 & 41.7 & 29.9 \\
\hline 0.3 & 53.7 & 42.5 & 32.3 & 55.7 & 41.7 & 29.3 \\
\hline 0.4 & 52.9 & 42.4 & 32.1 & 55.6 & 40.9 & 28.7 \\
\hline 0.5 & 52.3 & 42.1 & 32.1 & 54.1 & 40.3 & 28.6 \\
\hline 0.6 & 52.6 & 41.9 & 32.2 & 53.7 & 39.7 & 28.3 \\
\hline
\end{tabular}

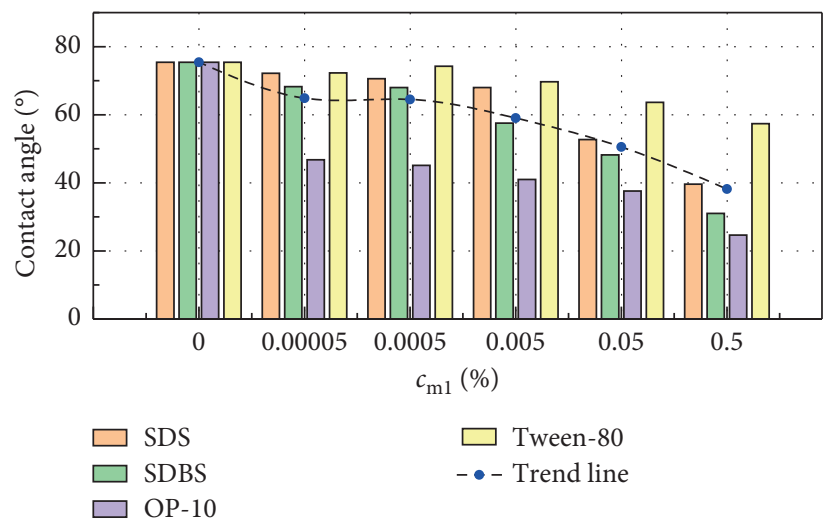

FIGURE 4: Contact angle of surfactant solution on the surface of coal dust tablet.

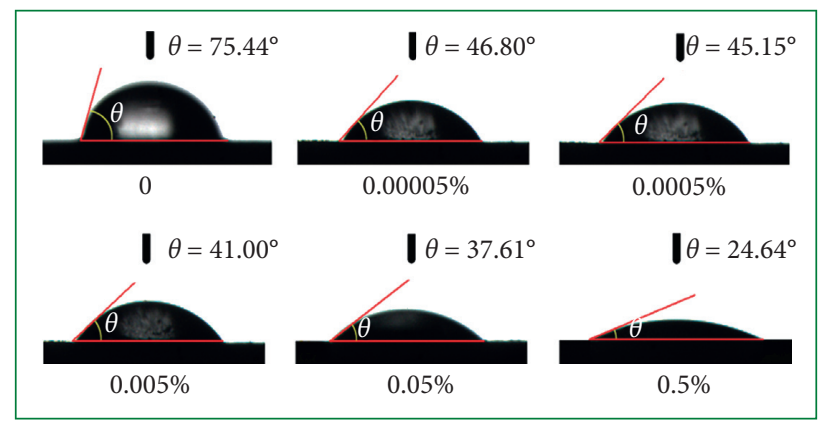

(a)

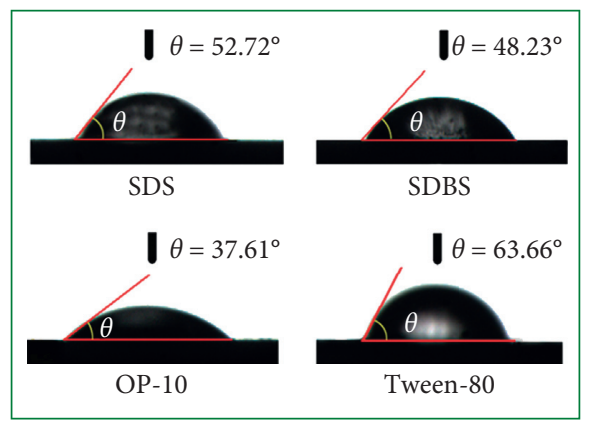

(b)

Figure 5: Contact angle projections of four surfactant solutions on coking coal tablets: (a) OP-10 solutions at different mass concentrations; (b) four surfactant solutions at $c_{\mathrm{m} 1}=0.05 \%$.

concentration, it can be seen that the wetting ability of the surfactant solution was different at the same mass concentration. The wetting ability of the four surfactants can be ordered as follows: OP-10 > SDBS > SDS > Tween-80, as shown in Figure 5(b).

From the contact angle projection in Figure 5, the OP10 solution had the optimal wetting ability and the minimum contact angle at the same mass concentration. At the same mass concentration, the SDBS solution had minimal surface tension. However, from equation (2), the contact angle was related to not only the surface tension $\gamma_{\mathrm{lg}}$ of the solution but also the tension $\gamma_{\mathrm{sl}}$ at solid/liquid interface. From the results of the electrophoresis experiments, the surface of coal dust was usually negatively charged, and the adsorption capacity of different types of surfactants was different. The surface active particles ionized from the anionic surfactant were negatively charged, which repelled the coal dust with negative charges on the surface. This repelling force was not conducive to the adsorption of the surfactant on the coal dust surface. Therefore, the anionic surfactant had a lower adsorption capacity on the surface of the coal dust than the nonionic surfactant. As a result, the nonionic surfactant had a lower solid/liquid interfacial tension than the anionic surfactant at the same mass concentration [50]. Consequently, considering the gasliquid surface tension and the liquid-solid interface tension, the nonionic surfactant had better wetting ability for coal dust than anionic surfactant. 


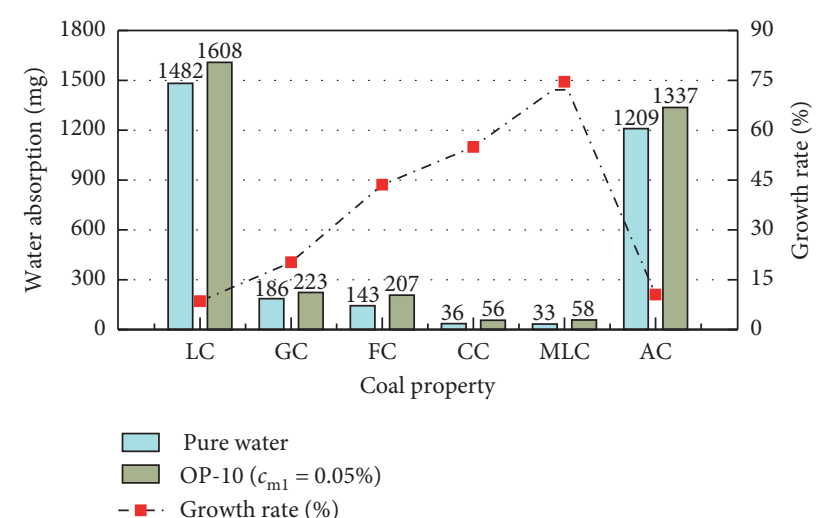

FIgURE 6: The reverse osmosis moisture of six coal dusts with different metamorphic degrees in pure water and OP-10 solution.

3.2.2. Effect of Coal Metamorphism. Figure 6 shows the reverse osmosis moisture of six coal dusts with different metamorphic degrees in pure water and OP-10 solution. From Figure 6, there were significant differences in the wettability of the six types of coal dust. Both anthracite and lignite had better wettability, while the other four types of coal dusts had relatively poor wettability. It can also be seen from the figure that the surfactant of OP-10 can effectively improve the wetting ability of the solution. The reverse osmosis moisture of the six kinds of coal dust in the surfactant solution was increased to different degrees compared with that in the pure water. From the growth rate curve in Figure 6, the surfactant had different effects on the improvement of the wettability of coal dust with different degrees of metamorphism. Overall, when wettability of the coal dust was poorer, the improvement effect by the surfactant solution was more significant and the growth rate of reverse osmosis moisture was higher. For example, the lignite and anthracite with better wettability had an increase in the reverse osmosis moisture absorption by only less than $15 \%$, while the coking coal and lean coal with poor wettability had a growth rate of more than $50 \%$.

According to the wetting theory, for a specific coal dust, the factors affecting the wetting ability of the liquid to the coal dust included the gas-liquid interfacial tension and the liquid-solid interfacial tension. In this experiment, since the same surfactant solution was used, the gas-liquid surface tension remained the same. At the same time, due to the different degrees of metamorphism of coal dust, the surface energy of the solids was different, resulting in a difference in the liquid-solid interfacial tension. For the coal dust with good wettability, the surface energy reached a small value, thus the surface-adsorbent surfactant had very limited influence on the liquid-solid interfacial tension. As a result, the improvement of the reverse osmosis moisture by the surfactant solution was not obvious. On the other hand, the coal dust with poor wettability had higher surface free energy, and the adsorption of the surfactant can greatly reduce the liquid-solid interface tension, thereby greatly improving the wettability.

The contact angles of the six types of coal dust were measured by a contact angle meter, and the relationship

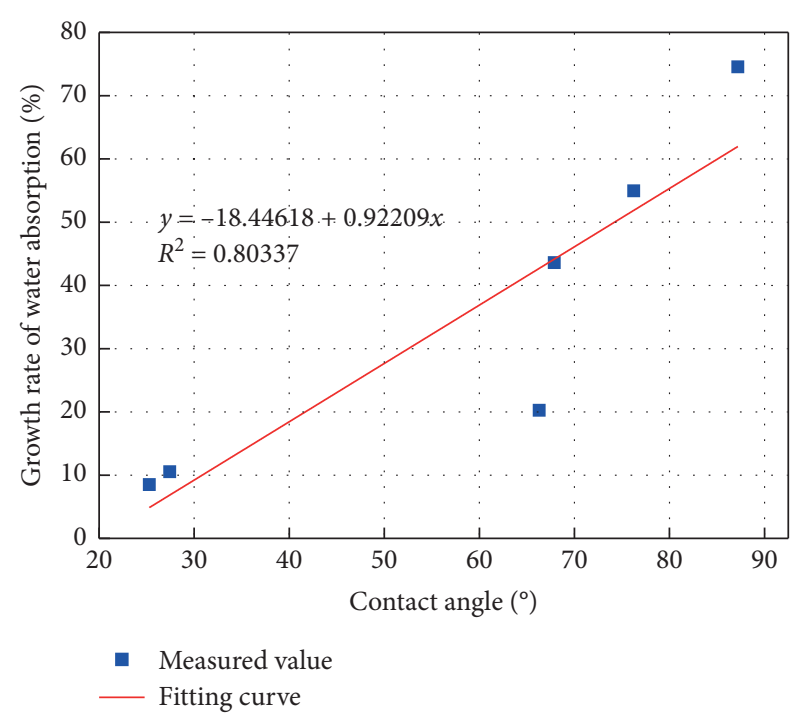

FIGURE 7: Relationship between the contact angle and the growth rate of reverse osmosis.

between the contact angle and the growth rate of reverse osmosis was fitted. The results are shown in Figure 7. It can be seen from Figure 7 that the growth rate of coal dust reverse osmosis moisture increased with the increase of the contact angle of coal dust. When the contact angle was larger, the effect of surfactant on the wettability of coal dust was more obvious. From the fitting results in Figure 7, the growth rate of reverse osmosis and the contact angle had a good linear correlation, and the correlation coefficient $R^{2}$ was 0.8034 .

3.2.3. Effect of Coal Dust Particle Size. Figure 8 shows the reverse osmosis moisture of coal dust with different particle sizes in pure water and OP-10 solution. From Figure 8, for the same coal, the reverse osmosis moisture absorption decreased with the decrease in the particle size of coal dust, indicating that the reduction in the particle size of coal dust can cause the decrease of the wettability. The results of microscopic characteristics of coal dust in [63] showed that as the particle size of coal dust decreased, the specific surface area of coal dust increased, and the oxygen-containing functional groups and internal pores exposed on the surface of coal dust decreased. As a result, the wettability of the coal dust decreased with the decrease in the particle size. From the growth rate curve of the moisture absorption in Figure 8, the improvement of the wettability of coal dust by surfactant solution was dependent on the particle sizes. In general, when the particle size of the coal dust was smaller, the improvement in the wettability by the surfactant solution was more obvious, and the growth rate of the reverse osmosis moisture absorption was higher.

The contact angle of the six particle sizes of coal dust was measured by a contact angle measurement instrument, and the relationship between the particle size and the moisture absorption rate was fitted. The results are shown in Figure 9. From Figure 9, the growth rate of the reverse osmosis moisture of coal dust increased with the increase in the 


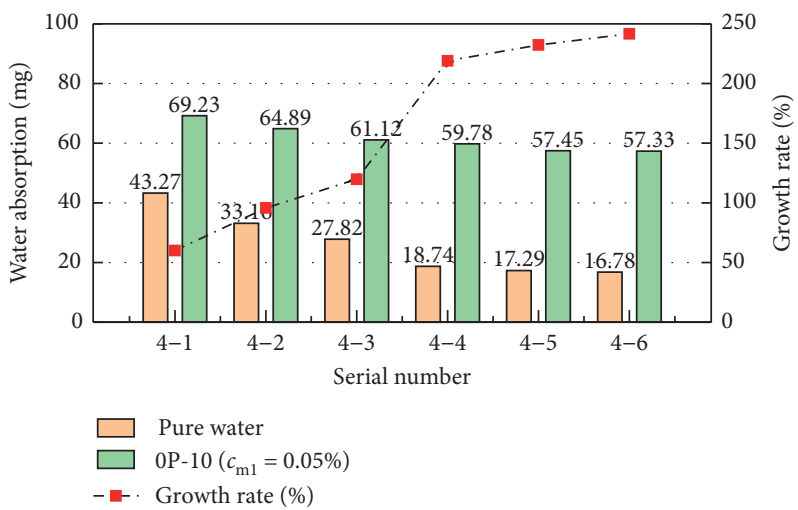

Figure 8: The reverse osmosis moisture of coal dust with different particle sizes in pure water and OP-10 solution.

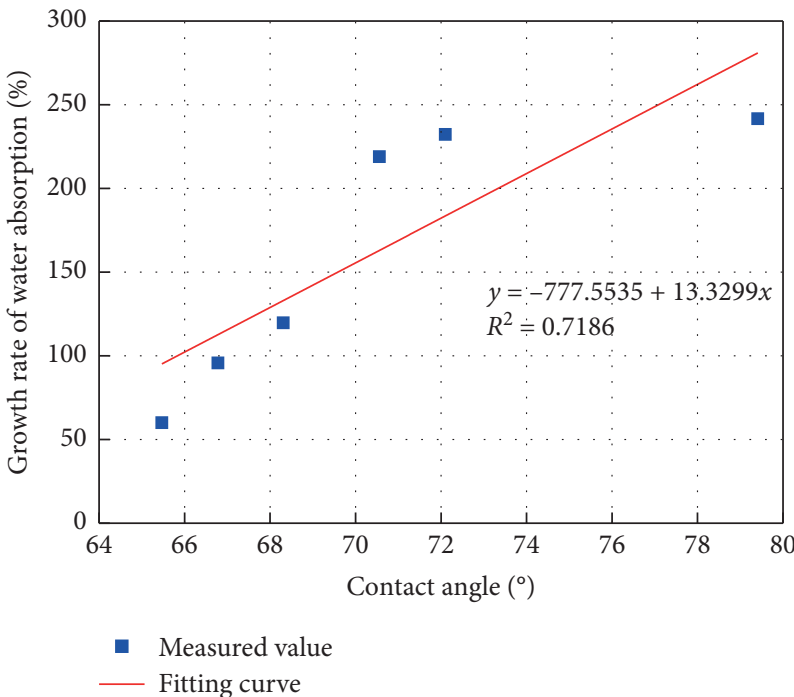

Figure 9: The relationship between the contact angle and the growth rate of reverse osmosis.

contact angle of coal dust. When the contact angle was larger, the effect of surfactant on the wettability of coal dust was more obvious. The fitting results from Figure 9 also indicated that the reverse osmosis growth rate and the contact angle had a good linear correlation, and the correlation coefficient $R^{2}$ was 0.7186 .

From the experimental results on the effect of the coal metamorphism degree and the coal dust particle size, it can be seen that in the design of dust-reduction scheme via spraying, the surfactant should be selected according to the degree of coal dust metamorphism and the particle size of coal dust. For the coal dust with better wettability, the effect of increasing the surfactant on the dust reduction was not obvious. For the coal dust with a large contact angle, adding a surfactant to the spraying water can significantly improve the wettability of the coal dust, thereby improving the dust-reduction effect via spraying. The growth rate of the reverse osmosis moisture absorption and the contact angle of coal dust maintained a good linear relationship. The growth rate of the reverse osmosis moisture absorption increased with the increase in the contact angle of coal dust. Therefore, when the effect of surfactants on the wettability of coal dust with different types or sizes was investigated, the improvement of wetting performance can be qualitatively and quantitatively evaluated according to the contact angle of the coal dust.

3.2.4. Effect of Additives. Figure 10 shows the effect of $\mathrm{Na}_{2} \mathrm{SO}_{4}$ on the reverse osmosis moisture absorption of the surfactant solution. From the figure, for the surfactant solutions with three different mass concentrations, the amount of reverse osmosis moisture of coal dust increased to different degrees by the adding of additives. In addition, as the mass concentration of the additives increased, the moisture absorption of coal dust continuously increased.

The inorganic salt additive, $\mathrm{Na}_{2} \mathrm{SO}_{4}$, was added to provide a large amount of $\mathrm{Na}^{+}$and $\mathrm{SO}_{4}^{2-}$ in the surfactant solution. These ions can neutralize the hydrophilic group charge of the surfactant adsorbed on the hydrophobic surface of the coal dust surface and reduce the electrostatic repulsion between the hydrophilic groups. Therefore, the hydrophobic surface of the coal dust allowed the density of hydrophilic group of the adsorbed surfactant to increase, which can convert more hydrophobic surfaces of the coal dust into a hydrophilic state, resulting in the increase of wettability and the increase in the reverse osmosis of coal 


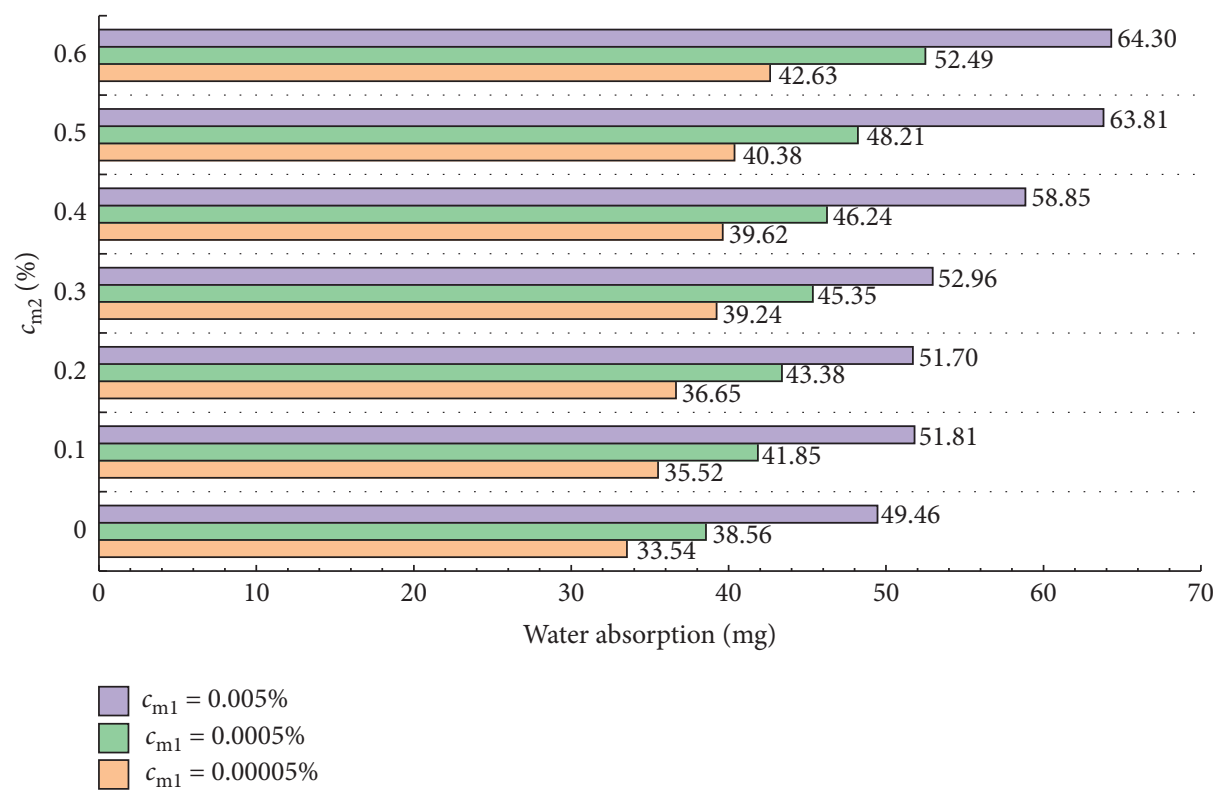

Figure 10: The effect of $\mathrm{Na}_{2} \mathrm{SO}_{4}$ on the reverse osmosis moisture absorption of the surfactant solution.

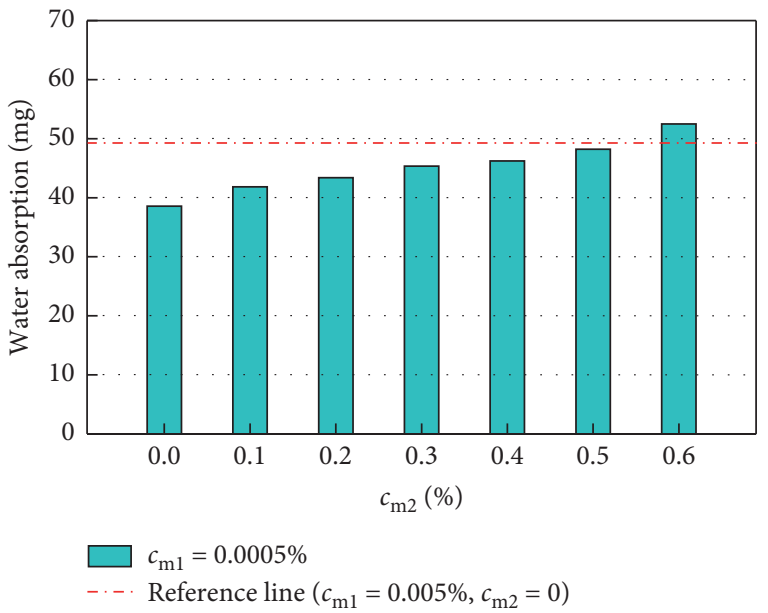

FIGURE 11: The reverse osmosis moisture of coal dust with different concentrations of addition, when $c_{\mathrm{m} 1}=0.0005 \%$.

dust. It can also be found from the experimental data that the addition of an appropriate amount of inorganic salt to the low concentration surfactant solution can achieve the wetting ability of a single surfactant solution with a high concentration. As shown in Figure 11, the reverse osmotic moisture absorption of the OP-10 solution with a mass concentration of $0.0005 \%$ was $38.56 \mathrm{mg}$ and the addition of a $0.5 \%$ inorganic salt additive to the solution can increase the reverse osmosis moisture to $48.21 \mathrm{mg}$. This reverse osmosis moisture was almost as high as that of the surfactant solution with the concentration of $0.005 \%$. The price of inorganic salts in the market is much lower than that of various surfactants. Therefore, the method of adding inorganic salt additives can reduce the amount of surfactants, thereby saving the cost of surfactants in the dust-reduction system via spraying.

\section{Conclusions}

In this study, through the experiments on surface tension, contact angle, and reverse osmosis, the wetting performance of the surfactant solutions for coal dust was investigated. The results of surface tension experiment showed that two types of surfactants, i.e., SDBS and OP-10, were superior to the other two surfactant in the reducing the surface tension. Both SDBS and OP-10 reached the CMC value at the concentration of $0.005 \%$. The addition of an additive further reduced the surface tension of the surfactant solution, but the change was not significant. The coal dust wetting experiment showed that, with the increase in the concentration of surfactants, the contact angle of the droplets on the coal dust tablets was continuously reduced, and the wetting ability of the surfactant solution was continuously improved. The OP-10 solution had the optimal wetting performance and the minimum contact angle at the same mass concentration. The growth rate of the reverse osmosis moisture of the surfactant solution relative to the pure water increased with the increase of the contact angle of the coal dust. The growth rate of the reverse osmosis and the contact angle of the coal dust had a good linear correlation. In addition to analyze the effect of surfactant solution on the wettability of the coal dust with different types or sizes, the improvement of the wetting performance can be evaluated qualitatively and quantitatively according to the contact angle of the coal dust. After adding inorganic salt additives, the reverse osmosis moisture absorption of coal dust increased to different degrees. As the mass concentration of additives increased, the moisture absorption of coal dust increased continuously.

\section{Data Availability}

The data used to support the findings of this study are included within the article. 


\section{Conflicts of Interest}

The authors declare that they have no conflicts of interest.

\section{Acknowledgments}

Financial support for this work, provided by the National Natural Science Foundation of China (No. 51574123) and the Scientific Research Project of Hunan Province Office of Education (No. 18A185), are gratefully acknowledged.

\section{References}

[1] G. Wang, C. Jiang, and J. Shen, "Deformation and water transport behaviors study of heterogenous coal using CTbased 3D simulation," International Journal of Coal Geology, vol. 211, 2019.

[2] L. Xin, Z.-t. Wang, G. Wang et al., “Technological aspects for underground coal gasification in steeply inclined thin coal seams at Zhongliangshan coal mine in China," Fuel, vol. 191, pp. 486-494, 2017.

[3] X. Ren, X. Hu, D. Xue et al., "Novel sodium silicate/polymer composite gels for the prevention of spontaneous combustion of coal," Journal of Hazardous Materials, vol. 371, pp. 643654, 2019

[4] M. Wu, X. Hu, Q. Zhang, D. Xue, and Y. Zhao, "Growth environment optimization for inducing bacterial mineralization and its application in concrete healing," Construction and Building Materials, vol. 209, pp. 631-643, 2019.

[5] Y. Li, P. Wang, R. Liu, and R. Gao, "Optimization of structural parameters and installation position of the wall-mounted air cylinder in the fully mechanized excavation face based on CFD and orthogonal design," Process Safety and Environmental Protection, vol. 130, pp. 344-358, 2019.

[6] G. Wang, X. J. Qin, J. N. Shen, Z. Y. Zhang, D. Y. Han, and C. H. Jiang, "Quantitative analysis of microscopic structure and gas seepage characteristics of low-rank coal based on CT three-dimensional reconstruction of CT images and fractal theory," Fuel, vol. 256, 2019.

[7] R. Liu, W. Cheng, Y. Yu, and Q. Xu, "Human factors analysis of major coal mine accidents in China based on the HFACSCM model and AHP method," International Journal of Industrial Ergonomics, vol. 68, pp. 270-279, 2018.

[8] M. Tao, Z. Li, W. Cao, X. Li, and C. Wu, "Stress redistribution of dynamic loading incident with arbitrary waveform through a circular cavity," International Journal for Numerical and Analytical Methods in Geomechanics, vol. 43, no. 6, pp. 1279-1299, 2019.

[9] M. Tao, H. Zhao, X. Li, X. Li, and K. Du, "Failure characteristics and stress distribution of pre-stressed rock specimen with circular cavity subjected to dynamic loading," Tunnelling and Underground Space Technology, vol. 81, pp. 1-15, 2018.

[10] J. Wang, G. Zhou, X. Wei, and S. Wang, "Experimental characterization of multi-nozzle atomization interference for dust reduction between hydraulic supports at a fully mechanized coal mining face," Environmental Science and Pollution Research, vol. 26, no. 10, pp. 10023-10036, 2019.

[11] Z. Xiu, W. Nie, D. Chen et al., "Numerical simulation study on the coupling mechanism of composite-source airflow-dust field in a fully mechanized caving face," Powder Technology, vol. 356, pp. 443-457, 2019.

[12] Q. Liu, W. Nie, Y. Hua et al., "A study on the dust control effect of the dust extraction system in TBM construction tunnels based on CFD computer simulation technology,"
Advanced Powder Technology, vol. 30, no. 10, pp. 2059-2075, 2019.

[13] Y. Ma, G. Zhou, J. Ding, S. Li, and G. Wang, "Preparation and characterization of an agglomeration-cementing agent for dust suppression in open pit coal mining," Cellulose, vol. 25, no. 7, pp. 4011-4029, 2018.

[14] Y. J. Li, P. F. Wang, R. H. Liu, Y. D. Jiang, and H. Han, "Determination of the optimal axial-to-radial flow ratio of the wall-mounted swirling ventilation in fully mechanized excavation face," Powder Technology, vol. 32, 2019.

[15] W. Zhou, H. Wang, D. Wang, K. Zhang, Y. Du, and H. Yang, "The effect of geometries and cutting parameters of conical pick on the characteristics of dust generation: experimental investigation and theoretical exploration," Fuel Processing Technology, vol. 198, Article ID 106243, 2020.

[16] P. Wang, C. Tian, R. Liu, and J. Wang, "Mathematical model for multivariate nonlinear prediction of SMD of X-type swirl pressure nozzles," Process Safety and Environmental Protection, vol. 125, pp. 228-237, 2019.

[17] P. Wang, Y. Li, R. Liu, and Y. Shi, "Effects of forced-toexhaust ratio of air volume on dust control of wall-attached swirling ventilation for mechanized excavation face," Tunnelling and Underground Space Technology, vol. 90, pp. 194-207, 2019.

[18] W. Zhou, W. Nie, C. Liu et al., "Modelling of ventilation and dust control effects during tunnel construction," International Journal of Mechanical Sciences, vol. 160, pp. 358-371, 2019.

[19] P. Cai, W. Nie, D. Chen, S. Yang, and Z. Liu, "Effect of air flowrate on pollutant dispersion pattern of coal dust particles at fully mechanized mining face based on numerical simulation," Fuel, vol. 239, pp. 623-635, 2019.

[20] S. J. Shi, P. F. Wang, R. H. Liu, X. H. Tan, and W. Zhang, "Numerical simulation and engineering application of coalbed water injection," Mathematical Problems in Engineering, vol. 2019, Article ID 6309160, 2019.

[21] T. Charinpanitkul and W. Tanthapanichakoon, "Deterministic model of open-space dust removal system using water spray nozzle: effects of polydispersity of water droplet and dust particle," Separation and Purification Technology, vol. 77, no. 3, pp. 382-388, 2011.

[22] H. Wang, J. Wu, Y. Du, and D. Wang, "Investigation on the atomization characteristics of a solid-cone spray for dust reduction at low and medium pressures," Advanced Powder Technology, vol. 30, no. 5, pp. 903-910, 2019.

[23] P. Wang, Y. Shi, L. Zhang, and Y. Li, "Effect of structural parameters on atomization characteristics and dust reduction performance of internal-mixing air-assisted atomizer nozzle," Process Safety and Environmental Protection, vol. 128, pp. 316-328, 2019.

[24] H. Peng, W. Nie, H. Yu et al., "Research on mine dust suppression by spraying: development of an air-assisted PM10 control device based on CFD technology," Advanced Powder Technology, vol. 30, no. 11, pp. 2588-2599, 2019.

[25] Z. Liu, W. Nie, H. Peng, S. Yang, D. Chen, and Q. Liu, “The effects of the spraying pressure and nozzle orifice diameter on the atomizing rules and dust suppression performances of an external spraying system in a fully-mechanized excavation face," Powder Technology, vol. 350, pp. 62-80, 2019.

[26] P. Wang, K. Zhang, and R. Liu, "Influence of air supply pressure on atomization characteristics and dust-suppression efficiency of internal-mixing air-assisted atomizing nozzle," Powder Technology, vol. 355, pp. 393-407, 2019.

[27] H. Han, P. F. Wang, Y. J. Li, R. H. Liu, and C. Tian, "Effect of water supply pressure on atomization characteristics and 
dust-reduction efficiency of internal mixing air atomizing nozzle," Advanced Powder Technology, vol. 45, 2019.

[28] H. Wang, S. He, G. Xie, X. Chen, and B. Qin, "Study of the mechanism by which magnetization reduces dust suppressant usage," Colloids and Surfaces A: Physicochemical and Engineering Aspects, vol. 558, pp. 16-22, 2018.

[29] S. Yang, W. Nie, S. Lv et al., "Effects of spraying pressure and installation angle of nozzles on atomization characteristics of external spraying system at a fully-mechanized mining face," Powder Technology, vol. 343, pp. 754-764, 2019.

[30] H. Peng, W. Nie, P. Cai, Q. Liu, Z. Liu, and S. Yang, "Development of a novel wind-assisted centralized spraying dedusting device for dust suppression in a fully mechanized mining face," Environmental Science and Pollution Research, vol. 26, no. 4, pp. 3292-3307, 2019.

[31] H. Wang, Y. Du, X. Wei, and X. He, “An experimental comparison of the spray performance of typical water-based dust reduction media," Powder Technology, vol. 345, pp. 580-588, 2019.

[32] H. T. Wang, W. F. Xuan, Z. Z. Qin, and B. T. Zhang, "Experimental investigation of the properties of dust suppressants after magnetic-field treatment and mechanism exploration," Powder Technology, vol. 320, pp. 498-510, 2019.

[33] H. Wang, L. Zhang, D. Wang, and X. He, "Experimental investigation on the wettability of respirable coal dust based on infrared spectroscopy and contact angle analysis," Advanced Powder Technology, vol. 28, no. 12, pp. 3130-3139, 2017.

[34] Q. Zhou, B. Qin, F. Wang, H. Wang, J. Hou, and Z. Wang, "Effects of droplet formation patterns on the atomization characteristics of a dust removal spray in a coal cutter," Powder Technology, vol. 344, pp. 570-580, 2019.

[35] Q. Zhou, B. Qin, F. Wang, and H. Wang, "Experimental investigation on the performance of a novel magnetized apparatus used to improve the dust suppression ability of surfactant-magnetized water," Powder Technology, vol. 354, pp. 149-157, 2019.

[36] G. Xu, Y. Chen, J. Eksteen, and J. Xu, "Surfactant-aided coal dust suppression: a review of evaluation methods and influencing factors," Science of the Total Environment, vol. 639, pp. 1060-1076, 2018.

[37] G. Xu, X. Ding, M. Kuruppu, W. Zhou, and W. Biswas, "Research and application of non-traditional chemical stabilizers on bauxite residue (red sand) dust control, a review," Science of The Total Environment, vol. 616-617, pp. 1552-1565, 2018.

[38] N. Dombrowski and W. R. Johns, "The aerodynamic instability and disintegration of viscous liquid sheets," Chemical Engineering Science, vol. 18, no. 3, pp. 203-214, 1963.

[39] H. R. Ai, "The change law of dynamic surface tension of surfactant dampening solution," Journal of Yichun University, vol. 36, pp. 29-31, 2014.

[40] H. M. Fan, Y. N. Zhang, and J. Zhang, "Dynamic surface adsorption properties of sodium dodecyl sulfate solution," Acta Physico-Chimica Sinica, vol. 29, pp. 351-357, 2013.

[41] J. K. Wang, H. K. Zhang, and H. Q. Lu, "Study on dynamic surface tension of surfactants," Chemical Technology, vol. 2, pp. 39-42, 2005.

[42] H. Zhang, W. Nie, H. Wang, Q. Bao, H. Jin, and Y. Liu, "Preparation and experimental dust suppression performance characterization of a novel guar gum-modification-based environmentally-friendly degradable dust suppressant," Powder Technology, vol. 339, pp. 314-325, 2018.
[43] W. Q. Zhang, P. Liu, and K. K. Lv, "Experimental study on compound surfactant with coal dust hydrophilicity," Coal Technology, vol. 33, pp. 288-290, 2014.

[44] W. Li, F. F. Liu, and X. B. Zhang, "A study on synergism in non-ideal ternary mixture of surfactant C12BE-SDS-TX-10," Chinese Journal of Applied Chemistry, vol. 23, pp. 907-912, 2006.

[45] G. X. He, H. J. Sun, H. T. Zan, and H. Wu, "Effect of inorganic salt on surface tension of SDS solution," Chemical Industry Times, vol. 22, pp. 42-44, 2008.

[46] J. Du and X. C. Zeng, "An investigation on the variation of critical micelle concentrations of CTAB and SDS surfactant influenced by salts," Journal of Sichuan University (Nature Science Edition), vol. 39, pp. 733-736, 2002.

[47] R. Wang, G. Dorr, A. Hewitt, and J. Cooper-White, "Impacts of polymer/surfactant interactions on spray drift," Colloids and Surfaces A: Physicochemical and Engineering Aspects, vol. 500, pp. 88-97, 2016.

[48] J. Y. Li, Y. P. Lu, and Y. X. Zhao, "Modification experiment of surfactant wettability to coal," Coal Technology, vol. 35, no. 8, pp. 189-191, 2016.

[49] H. Tang, L. Zhao, W. Sun, Y. Hu, and H. Han, "Surface characteristics and wettability enhancement of respirable sintering dust by nonionic surfactant," Colloids and Surfaces A: Physicochemical and Engineering Aspects, vol. 509, pp. 323-333, 2016.

[50] J. Yang, Y. W. Tan, and Z. H. Wang, "Study on surface characteristics and wetting mechanism of coal dust," Journal of China Coal Society, vol. 7, pp. 737-740, 2007.

[51] C. Wu and D. S. Gu, "Study on the improvement of wetting coal dust by anionic surfactant by $\mathrm{Na}_{2} \mathrm{SO}_{4}$," Journal of Safety and Environment, vol. 2, pp. 45-49, 2001.

[52] M. W. Tessum and P. C. Raynor, "Effects of spray surfactant and particle charge on respirable coal dust capture," Safety and Health at Work, vol. 8, pp. 296-305, 2007.

[53] H. B. Jiang, Y. L. Xiao, and W. Zhao, "Study on wetting property of coal dust by new surfactant solution," China Safety Science and Technology, vol. 9, no. 6, pp. 11-15, 2013.

[54] W. Liu, W. M. Cheng, and Y. B. Yu, "Experimental and application research of surfactant dust suppression in fully mechanized caving face," Mining Safety \& Environmental Protection, vol. 39, pp. 1-3, 2012.

[55] Y. Chen, G. Xu, J. Huang, J. Eksteen, X. Liu, and Z. Zhao, "Characterization of coal particles wettability in surfactant solution by using four laboratory static tests," Colloids and Surfaces A: Physicochemical and Engineering Aspects, vol. 567, pp. 304-312, 2019.

[56] Q. Bao, W. Nie, C. Q. Liu, Y. H. Zhang, H. H. Wang, and H. K. Jin, "Preparation and characterization of a binarygraft-based, water-absorbing dust suppressant for coal transportation," Journal of Applied Polymer Science, vol. 135, 2019.

[57] H. Jin, W. Nie, Y. Zhang et al., "Development of environmental friendly dust suppressant based on the modification of soybean protein isolate," Processes, vol. 7, no. 3, p. 165, 2019.

[58] J. C. Kumia, A. P. Sasmito, and A. S. Mujumdar, "Dust dispersion and management in underground mining faces," International Journal of Mining Science and Technology, vol. 24, pp. 39-44, 2014.

[59] K. Cybulski, B. Malich, and A. Wieczorek, "Evaluation of the effectiveness of coal and mine dust wetting," Journal of Sustainable Mining, vol. 14, no. 2, pp. 83-92, 2015.

[60] P. Wang, X. Tan, L. Zhang, Y. Li, and R. Liu, "Influence of particle diameter on the wettability of coal dust and the dust 
suppression efficiency via spraying," Process Safety and Environmental Protection, vol. 132, pp. 189-199, 2019.

[61] X. Z. Xie and G. Fu, "Discussion on coal wettability measuring method," Coal Science and Technology, vol. 32, pp. 65-68, 2004.

[62] Q. Li, B. Lin, S. Zhao, and H. Dai, "Surface physical properties and its effects on the wetting behaviors of respirable coal mine dust," Powder Technology, vol. 233, pp. 137-145, 2013.

[63] J. Yang, H. Xu, J. G. Gao, D. D. Liu, and Y. F. Wang, "Influence of particle size on surface characteristic and wetting mechanism of coal dust," Safety in Coal Mines, vol. 45, pp. 140-143, 2014. 